\title{
Development and Case Study Application of a Proxy- Generated Outcome Measure of Suffering for use with Clients with Illusory Mental Health
}

\author{
(C) 2020 Giulia Guglielmetti and Enrico Benelli
}

\begin{abstract}
The concept of illusory mental health is described as the rationale for needing an approach for working with individuals who are unaware of their suffering and are therefore unable to describe their problems through self-report instruments. The use of a nomothetic approach using self-report or clinician-generated standardised instruments is compared with an idiographic approach for working with such individuals. A case study is used to illustrate the development and first application of a Proxy-Generated Outcome Measure (PGOM) that allows clinicians, observers and researchers to trace an individualised understanding of a client's core sufferings and changes occurring during the process of psychotherapy. A comparison with a nomothetic outcome measure is also presented.
\end{abstract}

\section{Keywords}

Illusory Mental Health (IMH), Proxy-Generated Outcome Measure, idiographic, Psychodiagnostic Chart-2, nomothetic, client's implicit suffering, clinician's subjective experience, guided clinical judgment, systematic observation, psychotherapy outcome assessment, Psychodynamic Diagnostic Manual-2, psychodynamic psychotherapy.

\section{Introduction}

Illusory mental health $(\mathrm{IMH})$ is the phenomenon in which individuals do not recognize their own suffering as a defensive denial against awareness of threatening memories and emotions. It tends to be characterized by a need to see themselves as well adjusted despite underlying vulnerability (Shedler, Mayman \& Manis, 1993). In this sense, Shedler and colleagues suggest a distinction between clients who present mental health on self-reports but are judged distressed by clinicians (apparently healthy) and clients who present themselves as mentally healthy in correspondence with the clinicians' judgements (genuinely healthy). This phenomenon has an impact on a considerable part of the population, approximately 10\% - 20\% (Ward \& McLeod, 2018), and is characterized by low scores on symptom measures, by indications of high levels of mental health problems in projective and narrative techniques, and clinical judgement, with an observable discrepancy between different sources of data about existence of mental health difficulties (Shedler et al., 1993). Shedler, Kaninger \& Katz, (2003) provide a list of characteristics that are often observable in persons who exhibit $\mathrm{IMH}$, that includes: a predominantly negative affect tone, with manifestations of insecurity; the experience of the Other as malevolent (e.g. as sources of pain, punishment, frustration) and as acting in cruel and destructive ways; the presence of negative early memories concerning abandoning, unprotective, or abusive caregivers .Shedler (Shedler et al., 1993; Cousineau \& Shedler, 2006) notes that this phenomenon shows an important implication for practice, as it seems to coincide with a higher risk of developing physical health problems. Those individuals identified as having IMH are physiologically over-reactive and tend to express distress somatically with real physiological costs. Accordingly, a study conducted in Massachusetts by Bram, Gottschalk \& Leeds (2018) adds the possibility that IMH could reflect a deficit or defensive structural weakness in the ability to access and process painful feelings. If so, unrecognized and unprocessed emotional distress would, therefore, be experienced and expressed primarily on a somatic level. This perspective would also explain the chronic fatigue syndrome, which is characterized by medically unexplained fatigue: somatic symptoms are somatized manifestations of a defensive disavowal or deficit in emotional processing. Shedler and colleagues emphasize another important implication of IMH phenomenon for the psychotherapy outcome research, since it suggests that some 
feedback and monitoring tools may not provide accurate information about the client's situation. In particular, Cousineau \& Shedler (2006) highlight the limitations of self-report questionnaires and suggest that implicit measures have an important role to play in mental health research. Consistently, a Dutch study (Wineke, Eurelings-Bontekoe, Dijke, Moene \& Gool, 2015) conducted on clients with somatoform disorders - who report somatic complaints attributed to an unexplained medical condition - underlines how these clients tend to deny the influence of psychological factors on self-report measures, showing a favourable self-presentation which may be related to defensive denial that characterizes the phenomenon of IMH. The results of this study are in line with the increasing awareness that many psychological processes are implicit rather than explicit, and not accessible via selfreports (Shedler et al., 1993; Cousineau \& Shedler, 2006; Westen \& Shedler, 2007; Wineke et al., 2015).

Bringing further support to the usefulness of implicit procedures, the German study of Subic-Wrana and colleagues (as cited in Wineke et al., 2015) shows that among clients with somatoform disorders, low levels of emotional awareness - assessed with an implicit projective measure (LEAS) - are associated with a low level of impairments in self-reports. In this regard, Wineke and colleagues suggest that the utility of selfreport measures may be limited in clients who tend to describe themselves as overly positive among these instruments, such as those clients with somatoform disorders, and that future research should include observer ratings, complementary to self-reports.

The term nomothetic derives from the Greek word nomos meaning law, and is used in psychology to establish generalization, such as diagnosis, referring to objective classification under similar condition. The term idiographic comes from the Greek word idios meaning own, private, and refers to aspects of subjective experience that make each person unique (Pagnini, Gibbons \& Castelnuovo, 2012; McLeod, 2007). In 1937, Gordon Allport first introduced to American psychology the distinction between the idiographic and nomothetic approach, starting the ongoing philosophical debate in the field of psychological sciences regarding the theoretical and methodological assumptions that should guide personality research (Grice, 2004). Precisely, in clinical psychology, the debate addresses the classification of personality and other taxonomies, as well as the use of diagnosis (Pagnini, et al., 2012). On the one hand, nomotheists have argued that personality psychologists should focus on generalities and discover and quantify phenomena observed in groups of individuals. On the other hand, idiographists have argued that the field of personality should be primarily concerned with understanding the developmental history of individuals as well as their subjective interpretation and responsiveness to reality (Grice, 2004). Over the years, both approaches have claimed to be theoretically founded and scientifically valuable.

\section{Nomothetic Approach}

In recent decades, psychological problems have been defined primarily on the basis of observable symptoms and behaviors. According to a nomothetic approach, which establishes laws and generalizations based on the study of large groups of people, these observable aspects of psychotherapy process and outcome are assessed through appropriate instruments (e.g. questionnaire and structured interviews), by clients themselves (self-rated) or by an external observer (proxy-rated). This approach generates a hypotheticaldeductive thinking that identifies explanatory and generalizable aspects regarding how much an aspect is common and recurrent within an extended sample, to the detriment of subjective connotations. Indeed, the traditional use of nomothetic, standardized and selfrated measures, such as the Patient Health Questionnaire 9-item (PHQ-9; Spitzer, Kroenke \& Williams, 1999) that scores each of the nine DSM-5 criteria for symptoms of depression, locates individuals within a larger population on general factors and norms. Having said that, self-report measures have emerged that would seem not to be sensitive to factors or situations that could influence the quantitative change in scores, such as social desirability (Paulhaus, 1986; McLeod, 2001, Caputo, 2017).

In addition, a poor correspondence between quantitative and qualitative data has been observed in clients who tend to deny their own observable suffering (Shedler, et al., 1993). Such evidences call into question the reliability of the nomothetic self-report tools, as they seem to be affected by socially-desirable responding or self-deception (Shedler et al., 1993; Cousineau \& Shedler, 2006). Moreover, self-report measures of mental health, perceived stress, life events stress and mood states, do not predict health outcomes and do not detect those psychological processes that are implicit rather than explicit, and that are therefore not accessible via self-report tools (Cousineau \& Shedler, 2006). Indeed, these measures do not capture the implicit dimensions (unconscious) of the client's suffering. Since these implicit dimensions, for example the intensity of the sufferings, are excluded from the client's awareness, they cannot be evaluated with nomothetic self-report instruments from the client's explicit point of view. For these reasons, some practitioners resort to the use of nomothetic, proxy-rated measures, such as the Hamilton Depression Rating Scale (HDRS; Hamilton, 1960), the most widely-used clinician-administered 
scale to assess client's severity and change in depressive symptoms.

According to Millon (1991), to preserve the clinical utility, systems and tools for personality assessment should include both explicit/conscious and implicit/unconscious structures and processes. In the light of this, explicit and implicit measure should both be integrated in randomized controlled trails and in meta-analyse. Some currently available studies of alcohol expectancies include both explicit and implicit measures, supporting a model in which prediction of drinking might be optimized by combining the best assortment of both implicit and explicit tasks: specifically, the Reich, Below \& Goldman, 2010 study supports the added value offered by the use of implicit measurement. A recurring question in the field of psychotherapy outcome assessment is how to measure these unique aspects, caught by the idiographic approach, but tending to be overwhelmed by the nomothetic approach.

\section{Idiographic Approach}

Idiographic knowledge focuses on the peculiarities of a single individual and exalts subjectivity and personal connotations, generating an interpretative thinking aimed at a fuller understanding of a specific case, often through the use of case studies, unstructured interviews, direct observation and other qualitative impressions derived from diaries or archival records. From an historical point of view, the idiographic strategies in psychology were first espoused by Gordon Allport, who wrote that "as long as psychology deals with universals and not with particulars, it won't deal with much" (Allport, 1960, p. 146). Supporting an idiographic approach, Elliot and colleagues (2016) highlighted that clients have a unique clinical condition, with problems and manifestations that are specific to their own circumstances. They also affirmed that during the last two decades, existing idiographic approaches use client generated outcome measures (CGOMs) to assess the client's self-rated explicit distress. Nowadays, the three most used CGOMs are: Goal Attainment Scaling (GAS; Kiresuk \& Sherman, 1968 [as cited in Elliot et al., 2016]), Psychological Outcome Profiles (PSYCHLOPS; Ashworth et al., 2004 [as cited in Elliot et al., 2016]), and the simplified version of the Personal Questionnaire (PQ; Elliott, Mack, \& Shapiro, 1999; Elliot, et al., 2016). The simplified $P Q$ is the most recognized and individualized idiographic CGOM to assess client's self-rated core problems; it helps clinicians from a wide range of theoretical orientations (psychodynamic, humanistic-experiential cognitive-behavioral) to individualize a range of client's specific psychological difficulties or central problems. The client is guided by the clinician (intake worker, therapist or researcher) during a process of developing a list of problem statements, describing in client's words what they want to work on in treatment; the client then rates these explicit problems on a seven-point scale. Once $P Q$ is constructed, clients typically complete the $P Q$ at the beginning of each therapy session (Elliot et al., 2016). The simplified version of $P Q$ is the most widely used idiographic CGOM as it has demonstrated sound psychometric properties and various clinical utilities, including: usefulness for session-to-session outcome monitoring; enhancement of knowledge of clientspecific explicit complaints; and clinical decision making (Elliot et al., 2016).

Despite their growing popularity, idiographic selfreport CGOMs have been viewed with some skepticism and criticized as both cumbersome and lacking sufficient psychometric evidence. Indeed, Mintz and Kiesler (1982 [as cited in Elliot et al., 2016]) noted that many studies using these techniques have not specified the manner of eliciting items or calculating scores from one study to the next. A second problem is the limited psychometric data for these measures, including empirical evidence for their validity, although Elliot and colleagues (2016) reported psychometric analyses of PQ. Another limitation of CGOMs is that clients can report only explicit problems and suffering that they perceive at a conscious or preconscious level. Indeed, in the simplified PQ, when the therapist helps the client to refine the items, the client describes own problems through a self-report clientgenerated outcome measure; it follows that these aspects of suffering are perceived by the client only at an explicit (conscious or preconscious) level. In addition, Elliot and colleagues $(1999,2016)$ noted that asking the client to complete the $P Q$ requires extra time and human resources (e.g., two or three additional sessions for the construction of the items). Moreover, this measure could lead to the risk of an excessive focus on the client's explicit point of view. For example, we know that clients may not be aware of some implicit dimensions (such as feelings, wishes, desires) and that it may be difficult for clients to attribute the same meaning to the items they had constructed at the beginning of the therapy, as the very meaning of the problems change, as well as their own global network of meanings. Furthermore, the use of the simplified $P Q$ may be strenuous and overcoming with some clients, with the risk of excessive structuring of the setting with clients whose need is to express their lack or overabundance of personality structure.

\section{Aims of the Study}

The first aim of our study is to report the analysis of a psychotherapy single case that is representative of those clinical cases in which clients fall in the healthy population (Shedler, et al., 1993; Shedler, et al., 2003) although direct observation or detailed examination of the session video recordings and transcripts shows a clinical suffering that would need to be adequately treated. Indeed, the subject studied in our clinical case 
obtained some values that placed them below the clinical threshold in the self-report nomothetic measures (BDI-II, Beck, Steer, \& Brown, 1996; STAIY2, Spielberger, Gorsuch, Lushene, Vagg \& Jacobs, 1983; CORE-OM, Evans, et al., 2002) whilst proxy compilation of a nomothetic measure (PDC-2, III Section; Gordon \& Bornstein, 2015) by a judgeobserver revealed moderate suffering.

The second aim of this study is to present an idiographic, proxy-rated and implicit version of the simplified $P Q$, that we have called Proxy Personal Questionnaire (PPQ), proxy-generated since it is a practitioner-generated. When the idiographic, explicit, self-rated simplified $P Q$ is not available, or when it is necessary to use more agile and accessible instruments than those generated by the client, distress themes or problems can be identified by a single judging practitioner (clinician or researcher) with the PPQ, through a systematic and detailed observation of video or audio recordings of therapy sessions. Specifically, the therapist conceptualizes the problems referring to the client's explicit words, conflicts, decisions and feelings, and analyzes implicit dimensions of distress such as pervasiveness and severity of suffering.

Nowadays there is evidence that to understand symptoms, we must know something about the person who hosts them (Lingiardi \& McWilliams, 2017; Westen, Gabbard, \& Blagov, 2006), and that both mental health and psychopathology involve many subtle features of human functioning (e.g., affect tolerance, regulation and expression; coping strategies and defenses; capacities for understanding self and others; quality of relationships) that are usually implicit and cannot be evaluated with selfreport measures because of exclusion from the client's awareness.

We followed also the criticisms that Elliot himself highlighted about the use of the $P Q$ in the simplified version: $P P Q$ allows the clinician to use subjective experience about the relationship with the client as a valuable resource, rather than focusing only on the individual patient's point of view (Dazzi, Lingiardi \& Gazzillo, 2009). Furthermore, this allows the clinician to understand in a more detailed and individualized manner the client's specific core problems and sufferings without over-structuring.

The third aim of the present study is to compare the $P P Q$ with PDC-2, the 12 nomothetic implicit categories of the proxy, recognized Psychodiagnostic Chart (PDC-2; Gordon \& Bornstein, 2015). Gordon \& Bornstein (2012) stated that the Psychodynamic Diagnostic Manual (PDM Task Force, 2006) needed a short, practical tool to guide practitioners through the sections of its taxonomy and Lingiardi \& McWilliams (2017) developed PDM-2 based on PDC-2 validated by Gordon \& Bornstein $(2015,2018)$. We observed that PPQ and PDM-2 share the same topical areas of psychological distress, as explained below.

\section{Methodology}

Client

The client, a man aged 23, was recruited via an announcement by the Department of Philosophy in a large city in southern Italy. He received 16 weekly private sessions over 5 months, in a professional office. No fees were payable as he was taking part in the research.

Having attended two years of university studies in a subject chosen to meet his father's expectations of him joining the family business, the client had felt the need to differentiate himself and had left home to live in a large city and study a different subject at university.

In video recordings, the client can be seen reporting on uncontrollable rage in situations in which he feels unrecognised or overwhelmed by strangers, leading to impulsive and aggressive acts towards others, to the point of putting his own safety at risk. The patient also refers to feeling sometimes as if he is divided into two, observing opposing and conflictual parts of himself, without being able to understand the phenomenon itself. $\mathrm{He}$ also reports that he has several friends and has had some stable emotional relationship, including a satisfying and positive relationship for a few months with a girl of the same age. However, a prototypical relational pattern emerges that if the client does not feel recognised, he has difficulties in expressing his needs and protecting his own interests, and tends to close down and withdraw from the relationship.

As indicated below, the quantitative self-report nomothetic measures gave subclinical (healthy) scores. However, the first qualitative screening of the client by an independent researcher during the assessment phase, as well as the client's anamnesis, highlighted the presence of suffering (e.g. the impulsiveness that drove the client into a sports accident).

\section{Ethical Protocol}

The research protocol followed the requirements of the Ethical Code for Research in Psychotherapy of the Italian Association of Psychology, and the American Psychological Association guidelines on the rights and confidentiality of research participants, and was approved by the Ethical Committee of the University of Padua. Before entering treatment, the client received an information pack, including a detailed description of the research protocol, and gave a signed informed consent and written permission to include segments of disguised transcripts of sessions or interviews within scientific articles or conference presentations. The client was informed that he would have received the therapy even if he decided not to participate in the 
research and that he was able to withdraw from the study at any point, without any negative impact on the therapy. All aspects of the case material have been disguised, so neither the client nor third parties are identifiable. All changes are made in such a way that does not lead the reader to draw false conclusions related to the described clinical phenomena.

Self-rated quantitative measure

Before, during and after the end of therapy, client data were gathered by an independent researcher, and blinded concerning diagnosis, treatment plan, therapeutic process, and outcome.

Before the start of the therapy (assessment session) the client completed measures for depression - BDI-II - Beck Depression Inventory, $2^{\text {nd }}$ ed. (Beck, Steer, \& Brown, 1996), trait anxiety - STAI-Y2 - State Trait Anxiety Inventory (Spielberger, Gorsuch, Lushene, Vagg \& Jacobs, 1983) and overall distress - COREOM - Clinical Outcomes in Routine Evaluation (Evans, et al., 2002), using versions in Italian and corresponding norms.

The Italian clinical cut-off score of the BDI-II is considered equal to 12; moreover, according to a scalar criterion it is possible to define the explicit severity level: raw scores between 0 and 10 place the patient within a non-clinical threshold; scores between 11 and 14 indicate a 'form of vulnerability' to depression and place the subject in a clinical threshold; scores between 15 and 17 indicate a 'moderate' form of depression, while scores above 17 a form of 'severe' depression (Ghisi, Flebus, Montano, Sanavio \& Sica, 2006).

The STAI-Y2 is composed of 20 items, in which the patient evaluates, on a scale from 1 to $4(1=$ nothing, 4 = very much), how much the item statements are appropriate to his own behavior. The range of the total score is between 20 and 80 with a predictive threshold value of anxious symptoms placed at 40 . Moreover, according to an Italian normative value: scores between 40 and 50 indicate a 'mild' form of anxiety and place the patient within the clinical threshold; scores between 50 and 60 indicate 'moderate' anxiety, and scores above 60 indicate 'serious' anxiety (Barisone, Lerda, Ansaldi, De Vincenzo \& Angelini, 2004).

The CORE-OM is a self-report questionnaire composed of 34 items with a 5-point Likert rating. The Italian clinical cut-off score is equal to 10 . Moreover, it is possible to define the explicit severity level: raw scores between 6 and 9 indicate symptoms of 'low' suffering and place the patient within the subclinical threshold; scores between 10 and 14 indicate 'mild' suffering and place the subject in the clinical threshold; between 15 and 19 'moderate' suffering, between 20 and 24 'moderate / severe' suffering, and above 25 'serious' suffering (Palmieri, 2011).
These quantitative measures were administered to confirm that client scores fell below the cut-off for clinical significance (Jacobson \& Truax, 1991) and are shown in Table 1.

\begin{tabular}{|c|c|c|}
\hline & $\begin{array}{c}\text { Clinical Cut- } \\
\text { Off }\end{array}$ & $\begin{array}{c}\text { Assessment } \\
\text { Session }\end{array}$ \\
\hline $\begin{array}{c}\text { BDI-II } \\
\text { (depression) }\end{array}$ & $\geq 12$ & 6 \\
\hline $\begin{array}{c}\text { STAI-Y2 } \\
\text { (trait anxiety) }\end{array}$ & $\geq 40$ & 39 \\
\hline $\begin{array}{c}\text { sorelinical } \\
\text { (overall } \\
\text { distress) }\end{array}$ & $\geq 10$ & 5 \\
\hline
\end{tabular}

Note: BDI-II = Beck Depression Inventory-II (Beck, Steer \& Brown, 1996). STAI-Y2 = State-Trait Anxiety Inventory (Spielberger, et al., 1983). COREOM = Clinical Outcomes in Routine Evaluation-Outcome Measure (Evans et al., 2002).

Table 1: Quantitative assessment outcome for symptoms of depression, trait anxiety and overall distress

Over the course of the therapy the client completed a measure of the perceived empathy in psychotherapy: the Empathic Understanding Subscale of the Relationship Inventory (EU, Barrett-Lennard, 1986), administered by an independent interviewer who was a clinical psychologist during internship. This subscale is validated in the clinical context and is composed of 16 items presented with a scale ranging from " -3 " (= strongly disagree) to " +3 " (= strongly agree), without a neutral option. Total scores range between-48 and +48 , with higher scores indicating higher perceived empathy.

Client scores are shown in Figure 1. They increased by 13 points to finish at 31 , a good empathic understanding.

Three months after the end of therapy, to avoid a complacency effect in the client, a different independent interviewer who was a clinical psychologist with a training in $\mathrm{Cl}$ conducted the semistructured Change Interview $(\mathrm{Cl}$; Elliot, Slatick \& Urman, 2001) The content of this interview is reported below under Results, in terms of how it related to the $P P Q$ findings.

All data were kept blind from the therapist until the qualitative analysis of the case was completed. 


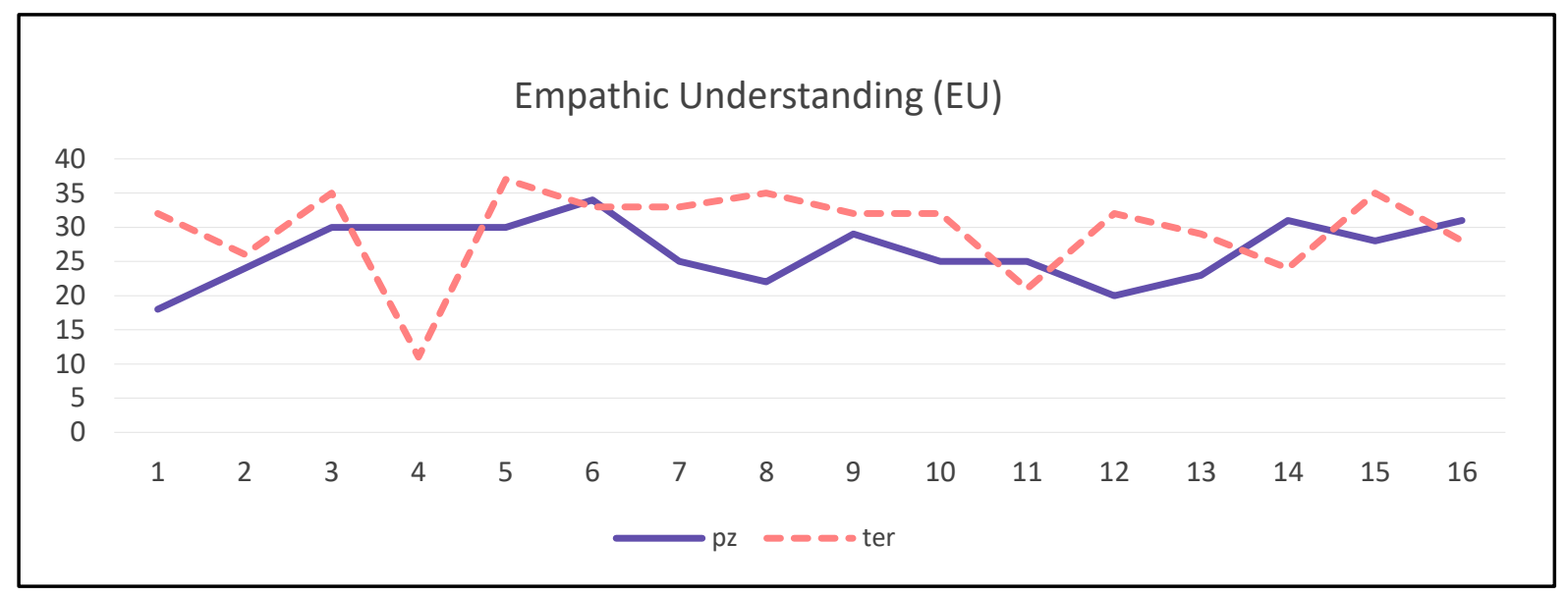

Figure 1: Trend of Empathic Understanding (EU) Subscale (Barrett-Lennard, 1986)

\section{Instruments used for the Study}

Psychodiagnostic Chart -2

The M-Axis of PDM-2 (Lingiardi \& McWilliams, 2017) considers 12 dimensions of healthy and pathological mental functioning about which clients are generally not aware, and would therefore be unable to describe themselves. These implicit dimensions were operationalized with the 12 categories of the Section III of PDC-2, which, according to Gordon and Bornstein $(2015,2018)$, is an application of a short, user-friendly and validated tool that can guide the practitioner (researcher or therapist) through all sections of the PDM taxonomy and integrates the use of PDM with the symptom classifications of the DSM5 (American Psychiatric Association, 2013) or the ICD-10 (World Health Organization, 1992). In this study, we consider Section III that requires the practitioner to determine the client's implicit overall mental functioning using a series of 5-point ratings for the 12 nomothetic dimensions of the M-axis, which include aspects of cognitive and affective processes, identity, relationships, defence, coping and selfawareness. These are summed to derive an implicit and proxy-rated overall severity score, with seven levels $(1=$ healthy; $7=$ severe defects). This process helps place PDM-2 diagnoses in the context of a client's overall psychological functioning.

\section{The PPQ}

The idiographic simplified PQ (Elliott et al, 1999, 2016) is an individualized client-generated outcome measure designed to measure changes in explicit psychological difficulties in a consistent manner. Items are first elicited from clients using a simple, open-ended Problem Description Form, which asks them to describe the problems that led them to seek therapy. A trained interviewer (e.g. an intake worker or researcher) then reviews this list and transfers the explicit problems onto individual note cards. During this process, the interviewer asks whether the client wants to include any problems for each of the following five topic areas: symptoms, mood, specific performance, relationships, and self-esteem. The interviewer then helps the client separate complex statements, clarifies ambiguous statements, and encourages the client to discard redundant statements to arrive at a list of approximately 10 simple, nonredundant problem statements. After the list of problems is finalized, the interviewer asks the client to order them in terms of importance, then to rate in terms of how much each has bothered them, and finally to rate problem duration (ranging from less than a month up to more than 10 years) On subsequent administrations, clients rate only severity for the past week.

While in the original idiographic, explicit, self-report and simplified version of $P Q$ the client is helped by the therapist to individualize the core problems, and therefore will report explicit (conscious and preconscious) problems, in our study we developed an idiographic, proxy-rated and implicit version of $P Q$ $P P Q$ - to identify implicit dimensions of client's suffering that the client is not able to assess about themself at the beginning of the psychotherapy. This proxy-generated version becomes an instrument that can monitor the client's implicit movements.

\section{PPQ Procedure}

In the spirit of triangulation, five judges (specifically four post-graduate psychology students from University of Padua and an expert clinician experienced in transactional analysis), conducted the study of a single psychotherapy case, consisting of sixteen sessions. They reviewed all the videotaped sessions and wrote up their versions of the case independently. Then, they met and systematically cross-analyzed their multiple case views; in particular, they conducted a hermeneutic analysis according to the HSCED protocol (Hermeneutic Single Case 
Design Efficacy; Elliot, 2002, 2009; Benelli, De Carlo, Biffi \& McLeod, 2015), qualitatively enriched by using the list of 56 criteria provided by Bohart and colleagues (Bohart, Berry \& Wicks, 2011; Bohart, Tallman, Byock \& Mackrill, 2011). Subsequently, upon mutual agreement, they traced six core problems or sufferings of the client, as they verbally emerged from the client's words in the video recordings of the initial sessions of the therapy. Then, one of the post-graduate students, supervised by the clinicians, used those six points to construct the PPQ as a summary of the most salient points within the session transcripts and the follow-up interview, assessing and adding (as in the examples below) the duration of the problems, and the implicit pervasiveness and severity of them, to formulate a detailed and individualized final guided clinical judgment regarding the client's sufferings and changes during the therapy.

\section{- Duration of problems - Client}

Sentences such as "I can't regulate my anger, since the age of kindergarten I had this problem and I was considered impetuous by my teachers" is indicative of a problem that lasts over ten years (score = 10), whereas "I do not understand what happened to me, I recently lost control of my anger, l've never been like this before" is considered a problem that lasts a few months or one year ( $($ core $=1$ ).

\section{- Pervasiveness}

The judge recognizes each relative duration and expresses the implicit pervasiveness of each suffering by summing the invested time (in terms of minutes) by both client and therapist to explore each problem, within each of the 16 sessions of the therapy, according to subjective perception and expressing these as percentages of time spent during each phase of the therapy.

\section{- Severity}

The judge attributes to each suffering a score based on subjective perception about the implicit severity of the client's suffering and adds them to obtain a global score. To facilitate comparisons and the formulation of the final clinical judgment of implicit sufferings and changes, the judge constructs three chronological versions of PPQ for each phase:

- $\quad P P Q$ Phase 1: Sessions 1 - 8. See Table A in Appendix.

- $\quad$ PPQ Phase 2: Sessions 9 - 16. See Table B in Appendix.

- $\quad$ PPQ Phase 3: 3-month follow-up. See Table C in Appendix.

In order to compare the final clinical judgement based on PPQ with the diagnostic inference gained through the PDC-2, the judge needs familiarity with the PDM-2 and access to diagnostic interview data and psychological assessment data to derive optimal PDC-
2 ratings, so that PDC- 2 versions can be compiled for the same three phases.

\section{Results \\ PDC-2 outcome}

The judge obtained for phase 1 of the therapy an overall score of 36 , indicative of the level of "moderate" implicit impairments in mental functioning (Table 2). Then she obtained for phase 2 of the therapy an overall score of 44 , indicative of the level of "mild" implicit impairments in mental functioning. Finally, the judge obtained for follow-up an overall score of 48 , indicative of the level of an "appropriate mental functioning with some implicit areas of difficulty.

Finally the judge inferred that the client had improved in each area of mental functioning, including the implicit area of defenses and coping, which at the beginning of the therapy had demonstrated to be the most compromised area of the client's mental functioning. For more details concerning PDC-2 outcome across all phases of the therapy see Table 2 and Figure 2.

The judge compared the final clinical judgment about the client's main sufferings and changes, guided by the idiographic $P P Q$ versions (Tables A, B, C in Appendix), with the diagnostic inference about client's implicit impairments in terms of mental functioning, based on scores that emerged from the nomothetic PDC-2 versions (Table 2). She found a good correspondence between the subjectively perceived severities of client's suffering (PPQ), and the client's mental functioning profiles (PDC-2). The correspondence between the two instruments has been found along each chronological phase of the therapy, as represented in Table 3.

According to the first phase of the therapy (session 18), both measures highlighted implicit moderate client's distress; in particular, $\mathrm{PPQ}$ for phase 1 reported an implicit "moderate" suffering, while PDC-2 for phase 1 indicated an implicit "moderate" impairment in mental functioning. According to the second phase of the therapy (session 9-16), both measures highlighted implicit mild client's distress; in particular PPQ for phase 2 reported an implicit "mild" suffering, while PDC-2 for phase 2 indicated an implicit "mild" impairment in mental functioning. Furthermore, according to the third phase of the therapy, PPQ for the follow up reported "less than mild" implicit suffering (severity average $\mathrm{score}=8.5$, which is half-way between mild and very mild), while PDC-2 for the follow-up indicated an implicit "appropriate mental functioning with some areas of difficulty". Therefore, across all phases of the therapy, the scores of both instruments seem to overlap, suggesting to correspond, at the end of the therapy, both to a proxyrated and implicit low-level of global severity concerning the client's suffering (see Table 3). 


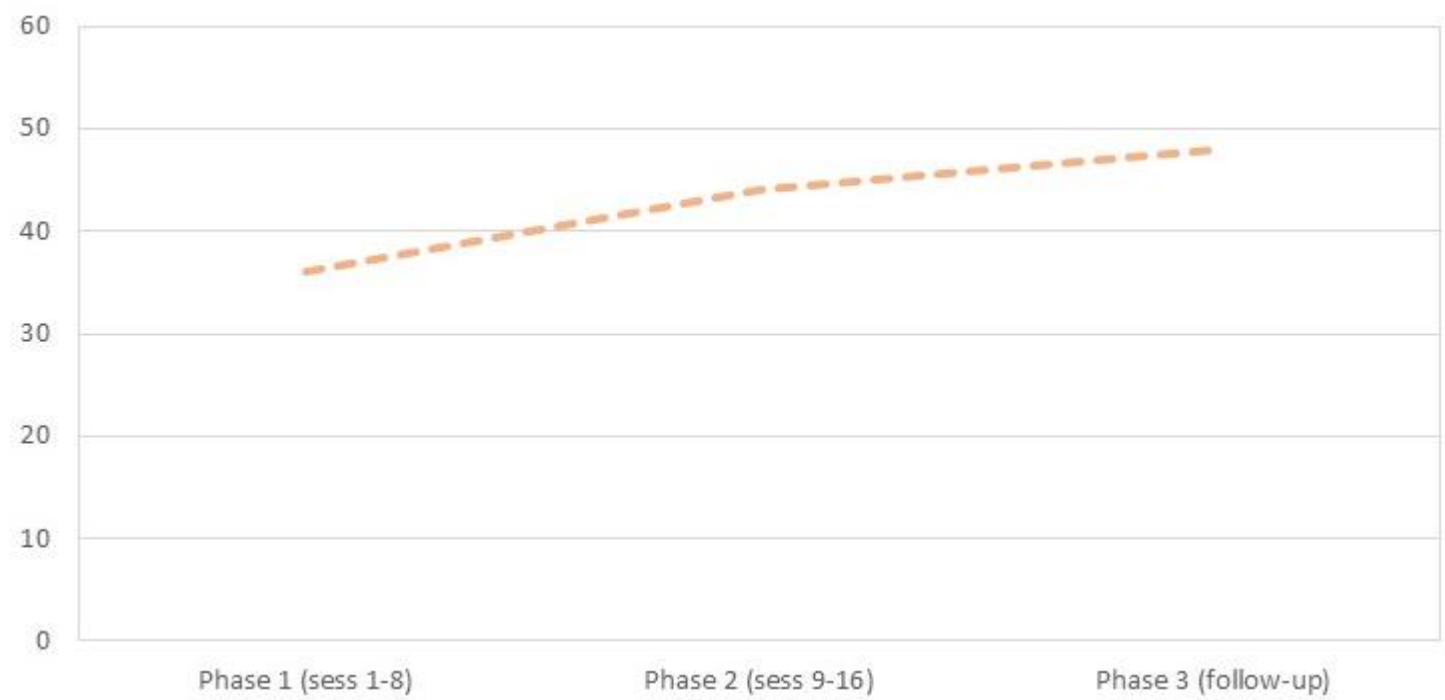

Figure 2: Level of mental functioning across the three phases of the therapy

\begin{tabular}{|c|c|c|c|}
\hline M-Axis CAPACITIES & $\begin{array}{c}\text { Phase } 1 \\
\text { (session 1- } \\
\text { 8) }\end{array}$ & $\begin{array}{c}\text { Phase } 2 \\
\text { (session 9- } \\
16 \text { ) }\end{array}$ & $\begin{array}{c}\text { Phase } 3 \\
\text { (3-month follow-up) }\end{array}$ \\
\hline \multicolumn{4}{|l|}{ Cognitive and affective processes } \\
\hline 1) Capacity for regulation, attention, and learning & 4 & 5 & 5 \\
\hline 2) Capacity for affective range, communication, and & 3 & 4 & 4 \\
\hline 3) Capacity for mentalization and reflective functioning & 3 & 4 & 4 \\
\hline \multicolumn{4}{|l|}{ Identity and relationships } \\
\hline 4) Capacity for differentiation and integration (identity) & 3 & 4 & 4 \\
\hline 5) Capacity for relationships and intimacy & 3 & 4 & 4 \\
\hline 6) Self-esteem regulation and quality of internal experience & 3 & 4 & 4 \\
\hline \multicolumn{4}{|l|}{ Defence and coping } \\
\hline 7) Impulse control and regulation & 2 & 2 & 3 \\
\hline 8) Defensive functioning & 3 & 3 & 4 \\
\hline 9) Adaptation, resiliency and strength & 3 & 3 & 4 \\
\hline \multicolumn{4}{|l|}{ Self-awareness and self-direction } \\
\hline 10) Self-observing capacities (psychological mindedness) & 3 & 4 & 4 \\
\hline 11) Capacity to construct and use internal standards and & 3 & 3 & 4 \\
\hline 12) Meaning and purpose & 3 & 4 & 4 \\
\hline Level of Impairment in Mental Functioning & $\begin{array}{c}36 \\
\text { Moderate }\end{array}$ & $\begin{array}{c}44 \\
\text { Mild }\end{array}$ & $\begin{array}{c}48 \\
\text { Appropriate with } \\
\text { Some Areas of } \\
\text { Difficulty }\end{array}$ \\
\hline
\end{tabular}

Note: M-Axis $=$ the axis of the $2^{\text {nd }}$ edition of Psychodynamic Diagnostic Manual (PDM-2; Lingiardi \& McWilliams, 2017) that considers 12 dimensions which describe the healthy and pathological mental functioning. These implicit dimensions of PDM-2 were operationalized in the III Section of the Psychodiagnostic Chart-2 (PDC-2; Gordon \& Bornstein, 2015, 2018) to derive the level of mental functioning

Table 2: Profile of mental functioning 


\begin{tabular}{|c|c|c|}
\hline Therapy Phases & $\begin{array}{c}\text { Severity Of Suffering } \\
\text { perceived by researcher } \\
\text { (PPQ) }\end{array}$ & $\begin{array}{c}\text { Profile Of Mental Functioning } \\
\text { perceived by clinician } \\
\text { (PDC-2) }\end{array}$ \\
\hline $\begin{array}{c}\mathbf{1}^{\text {st }} \text { phase } \\
(\text { Sessions 1-8) }\end{array}$ & Moderate & Moderate Impairment \\
\hline $\begin{array}{c}\mathbf{2}^{\text {nd }} \text { phase } \\
\text { (Sessions 9- 16) }\end{array}$ & Mild & Mild \\
\hline $\begin{array}{c}\mathbf{3}^{\text {rd }} \text { phase } \\
\text { (Follow-up) }\end{array}$ & Mild & $\begin{array}{c}\text { Appropriate with some areas of } \\
\text { difficulty }\end{array}$ \\
\hline
\end{tabular}

Table 3: Convergent comparison of PPQ with PDC-2

\section{PPQ outcome}

The five judges identified the following six problems or sufferings: 1 = "I cannot get angry with my father"; $2=$ "I would like to better manage my anger"; $3=$ "I feel invaded when I get provoked"; $4=$ "I need to feel recognized, or I close relationships"; $5=$ "I protect myself in the wrong way"; $6=$ "I do not understand how two different parts of myself can coexist" (Table 4).

These main problems, as well as their duration (Table 5 ), remained the same in all versions of the PPQ (see Tables A, B, C in Appendix) as they were taken into consideration by the client throughout the entire therapy.

The judge, from the analysis of videotaped sessions of phase 1 , subjectively perceived a "moderate" implicit suffering (severity average score $=6$;) in the client (PPQ for phase 1; see Table A in Appendix), observing that the most pervasive suffering in the first eight sessions of the therapy were related to the fourth and fifth problems: 4 = "I need to feel recognized, otherwise 'I close'"; $5=$ "I protect myself in the wrong way" (see Table 6).

The judge, from the analysis of videotaped sessions of phase 2, subjectively perceived a "mild" implicit suffering (severity average score $=8$ ) in the client $(P P Q$ for phase 2; see Table B in Appendix), observing that the most pervasive sufferings in the last eight sessions of the therapy were related to the first problem: $1=$ "I cannot get angry with my father"(see Table 6).

The judge, from the analysis of the 3-month follow-up transcription, subjectively perceived a "mild" implicit suffering (severity average score $=8.5$ ) in the client (PPQ for phase 3; see Table C in Appendix).
Pervasiveness was not assessed in the follow-up session.

The judge formulated the final clinical judgment observing improvements in the description of each problem, within each version of the PPQ (Figure 3)

During the follow-up, the client stated that he had given himself permission to feel new emotions that he had never felt before, especially in the family context [F-U transcription: lines 67-72], demonstrating a change in the first problem (1 = "I can't get angry with my father"), which is the most pervasive suffering during the last eight sessions of the therapy and one of the most enduring client's problem. The client also claimed to spend much less time angry and to be able to analyze and evaluate the most unpleasant situations, before reacting with anger [F-U transcription: lines 70-83], reporting a change in the second problem ( $2=$ "I would like to better manage my anger"), which is the second most enduring client's problem. The client reported that he had acquired new points of view, which before were inaccessible, and that he had learned to establish a relationship of trust with a stranger [F-U transcription: lines 164-168], indicating changes in the third and fourth problems $(3=$ "I feel invaded when I get provoked"; $4=$ "I need to be recognized otherwise "I close"'). In addition, client reported to be able to admit his own mistakes [F-U transcription: line 90], indicating a change in the fifth problem ( $5=$ "I protect myself in the wrong way "), and to have achieved a greater selfawareness and new points of view previously inaccessible [F-U transcription: line 137; lines 167168], suggesting a change in the sixth problem $(6=" \mathrm{I}$ do not understand how two different parts of myself could coexist). 


\begin{tabular}{|c|c|c|}
\hline Problems & Client's Words & Session \\
\hline $\begin{array}{l}\text { 1) I can't get angry } \\
\text { with my father }\end{array}$ & $\begin{array}{c}\text { - "I have the impossibility of getting angry with my dad. I do not } \\
\text { get angry directly with him, I show my anger but then I go into } \\
\text { the room and burst into tears". }\end{array}$ & 1 \\
\hline $\begin{array}{l}\text { 2) I would like to } \\
\text { better manage my } \\
\text { anger }\end{array}$ & $\begin{array}{l}\text { - "The thing that most ... presses me, I wish not to get angry } \\
\text { anymore. That is in the sense, get angry but with control. When I } \\
\text { get angry I become really blind, anger is my burden". } \\
\text { - "As a child I've always been called a rough boy, I liked fighting } \\
\text { games ... regardless of males, females ... just that ... makes me } \\
\text { feel bad because I still create more suffering ...". } \\
\text { - "I intimidate/lay hands on people generally. I scare people. I do } \\
\text { not want to hurt, but I scare them" [reacting instinctively]. }\end{array}$ & 3 \\
\hline $\begin{array}{c}\text { 3) I feel invaded } \\
\text { when I get provoked }\end{array}$ & $\begin{array}{l}\text { - "Sometimes I intimidate people by coming to blows. But not } \\
\text { beating them, just grabbing... when I feel invaded ". } \\
\text { - "Precedence is mine and you must give it to me, I've never } \\
\text { seen it like this way before. Transferred within [the aggressive } \\
\text { behavior] is an opposition... a provocation in short...". }\end{array}$ & 2 \\
\hline $\begin{array}{l}\text { 4) I need to be } \\
\text { recognized } \\
\text { otherwise I close } \\
\text { relationships }\end{array}$ & $\begin{array}{l}\text { - "I broke up with my ex-girlfriend for the same reason that I'm } \\
\text { frustrated because of my parents, that is the lack of } \\
\text { understanding ... I stopped loving her because once I was really } \\
\text { exposed and I had nerves uncovered, she rejected me, and } \\
\text { since then I have not been able to love her anymore ". }\end{array}$ & 1 \\
\hline $\begin{array}{l}\text { 5) I protect myself in } \\
\text { the wrong way }\end{array}$ & $\begin{array}{l}\text { - "I lent a valuable object to a friend of mine who destroyed it. } \\
\text { He did not compensate me and I gave up ". } \\
\text { - [dynamic of the accident] "My priority was more important than } \\
\text { my life". } \\
\text { - [dynamic of the accident] "I did not understand the extent of } \\
\text { what was going to happen. I remember the desire to challenge } \\
\text { the other athlete". }\end{array}$ & 1 \\
\hline $\begin{array}{l}\text { 6) I do not } \\
\text { understand how two } \\
\text { different parts of } \\
\text { myself can coexist }\end{array}$ & $\begin{array}{l}\text { - "Can they coexist?" [Parts of Self: one irascible and the other } \\
\text { sensitive]. } \\
\text { - "In the past it weighed me like a thing because they told me I } \\
\text { was neither flesh nor fowl". }\end{array}$ & 2 \\
\hline
\end{tabular}

Table 4: Core problems or sufferings: Client's Examples during Phase 1-3 Initial Sessions 


\begin{tabular}{|l|c|}
\hline \multicolumn{1}{|c|}{ Problems } & Duration (Years) \\
\hline 1 - I can't get angry with my father & $>10$ \\
\hline 2 - I would like to better manage my anger & $>10$ \\
\hline 3 - I feel invaded when I get provoked & 5 \\
\hline 4 - I need to be recognized otherwise I close & 3 \\
\hline 5 - I protect myself in the wrong way & 6 \\
\hline 6 - I do not understand how two different parts of my-self could coexist & 5 \\
\hline $\begin{array}{l}\text { Note. Scores represent the duration of each problems, which is expressed by the judge considering the client's statements within session } \\
\text { recordings: } 1=\text { few months or one year, 2- 10=2-10 years }\end{array}$ \\
\hline
\end{tabular}

Table 5: Duration of problems

\begin{tabular}{|l|c|c|}
\hline \multicolumn{1}{|c|}{ Problems } & Phase 1 & Phase 2 \\
\hline 1 - I can't get angry with my father & $16 \%$ & $32 \%$ \\
\hline 2 - I would like to better manage my anger & $8 \%$ & $8 \%$ \\
\hline 3 - I feel invaded when I get provoked & $7 \%$ & $5 \%$ \\
\hline 4 - I need to be recognized otherwise I close & $18 \%$ & $13 \%$ \\
\hline 5 - I protect myself in the wrong way & $18 \%$ & $7 \%$ \\
\hline 6 - I do not understand how two different parts of my-self could coexist & $9 \%$ & $9 \%$ \\
\hline $\begin{array}{l}\text { Note. Scores expressed in percentages indicate the pervasiveness of each suffering observed during each phase of therapy. Pervasiveness } \\
\text { was calculated by adding the minutes of exploration for each suffering by both client and therapist. }\end{array}$ & \\
\hline
\end{tabular}

Table 6: Pervasiveness of suffering

\section{$P P Q$}

60

50

40

30

20

10

0

Phase 1 (sess 1-8)

Phase 2 (sess 9-16)

Phase 3 (follow-up)

Figure 3: Severity of client's perceived suffering across the three phases of the therapy (PPQ) 


\section{Discussion}

In the present study, the nomothetic, self-rated and explicit quantitative data related to symptoms of depression (BDI-II), trait anxiety (STAI-Y2) and overall distress (CORE-OM) were evaluated only during the assessment session. Accordingly, they were not considered as outcome values, but rather as assessment values. These data emerged as subclinical, according to CS criterion (Jacobson \& Truax, 1991) and, therefore, no clinical pathology was detected. Despite this quantitative evidence, at a first screening of the client, a significant suffering emerges (e.g. the impulsiveness that drove the client into a sports accident), as well as from the client's anamnesis and from the analysis of the videotaped therapy sessions (PPQ). In addition, the researcher identified the client's change from a "low" to a "good" empathic understanding (according to EU subscale), since the beginning to the end of the therapy, with some non-significant trend deflections.

According to PDC-2, the judge inferred that the client, from the beginning to the end of the therapy, changed from a "moderate" to a "mild" impairment in mental functioning which, in the follow-up, became an "appropriate mental functioning with same area of difficulty". Specifically, from the beginning to the end of the therapy, the client improved by one point in each area of implicit mental functioning, including the area of defenses and coping, which at the beginning of the therapy demonstrated to be the most compromised area of the client's mental functioning (Table 2; Figure 2).

Moreover, the three idiographic, proxy, chronological versions of PPQ identified a change from a "moderate" to a "mild" level of implicit severity in client's sufferings. In addition, this new tool highlighted a change in the implicit pervasiveness of the client's central problems. Indeed, during the first part of the therapy the client's most pervasive conflicts were anchored to the need to feel recognized by others, and to learn how to better take care of himself. In the second half of the therapy the core sufferings of the client were more linked to the implicit inability to express healthy anger against the father. As explained above, pervasiveness was not assessed in the follow-up session (Tables A, B, C in Appendix; Figure 3).

Finally, the judge found a good correspondence between the idiographic severities of client's suffering (PPQ) and the client's nomothetic mental functioning profiles (PDC-2) along each chronological phase of the therapy (as represented in Table 3). Therefore, across all phases of the therapy, the scores of both idiographic and nomothetic, proxy, implicit instruments seem to overlap (e.g., at the end of the therapy, scores are both to a low-level global severity of client's suffering). Given such good correspondence, and since PDC-2 is recognized as a validated diagnostic measure (Gordon \& Bornstein, 2015, 2018) it was possible for the judge to verify the validity of the idiographic clinical judgment concerning the client's implicit problems and changes, as they proved to be corresponding to the scores that emerged from the nomothetic PDC-2 versions, in terms of proxy-rated and implicit severity of psychological distress.

This new idiographic, proxy, implicit version of the simplified $P Q$ does not foresee a quantitative collection of data starting from the client's attribution of scores, concerning the subjective importance perceived by the latter about the problems. Rather, PPQ provides a list of client's core problems and suffering, as they verbally emerged from the client's statements during the therapy sessions. This procedure, compared to the nomothetic categories of PDC-2, allows the practitioner to understand the client's sufferings in a more detailed way, and to enhance a deeper knowledge about the client's individualized situation and context, towards a fuller understanding of the complex and specific dynamics concerning the client's problems and sufferings. In the light of this, $P P Q$ allows the practitioner to formulate a guided clinical judgment about the client's problems and implicit sufferings, and to monitor the client's changes, during the course and at the end of the therapy. Moreover, to facilitate the comparison between the scores obtained by the PPQ and the PDC-2, the judge decided to use an implicit and proxy-rated measurement order for the implicit severity scale of $P P Q$ that is more similar to the implicit one used in PDC-2, rather than the explicit and self-rated measurement order used in the original version of $P Q$.

The good correspondence between the clinical judgment that emerged from the $P P Q$ and the diagnostic inference developed from the PDC-2, supports the correspondence between the two instruments. This correspondence is also strengthened by the commonality of the 5 topic areas of psychological distress between the two instruments (Table 7). Indeed, we observed that the client's idiographic six core problems (Table 4) identified by the judge to construct the PPQ, present five implicit common-topic psychological areas with the 12 nomothetic capacities scored by the judge in the PDC2 (Gordon \& Bornstein, 2015), and described in detail in the PDM-2 (Lingiardi \& McWilliams, 2017). These common implicit psychological areas are: impulse regulation, emotional regulation, mentalization, intimacy and the Self (Table 7).

We also observed that PPQ takes into account the same five idiographic areas proposed by the simplified PQ (Elliot, 1999; Elliot, et al., 2016): area of mood (problem 1 = "I can't get angry with my father"; problem $3=$ "I feel invaded when I get provoked"), area of 
symptoms (problem 2= "I would like to better manage my anger"); area of specific performance (problem 5= "I protect myself in the wrong way"), area of relationships (problem $4=" I$ need to be recognized elsewhere $<<$ I close $>>$ ") and the area of self-esteem (problem 6= "I do not understand if two different parts of my Self can coexist"). For more details see Table 7.

Besides, as training programs play a central role in mental health professions, we believe that it is crucial for both clinicians and researchers to start questioning in a scientific way which tools work, and which do not, in order to develop the clinical skills of the beginner clinicians during their training programs in psychotherapy. Coherently, we suggest that beyond its clinical and research utilities, this idiographic, proxy and implicit version of $P Q(P P Q)$ offers significant benefits in the field of the psychotherapy training. It has the potential to augment the usefulness of observing videotape sessions by helping trainees to focus on key areas related to the client's implicit and explicit dimensions of sufferings, and to develop their own idiographic clinical judgement about the therapy process and outcome. In the light of this, we believe that the process of learning to do the ratings by systematically reviewing training tapes, and to develop a clinical judgment to subsequently verify through a nomothetic, proxy, implicit validated diagnostic measure (PDC-2; Gordon \& Bornstein, 2015), could be considered a verifiable and replicable methodological procedure that, as well as having a valuable methodological soundness, can be highly educational and can be used in particular by clinicians in training to test and self-develop both their idiographic and nomothetic clinical skills. Indeed, the complementary use of idiographic PPQ with nomothetic PDC-2 can guide early-stage clinician to approach psychopathology and develop their skills as a professional clinician, as PPQ allows clinician to test their idiographic clinical judgments with nomothetic diagnostic inferences provided by PDC-2, respectively through the 5 problem areas of the simplified $P Q$ (Elliot, 1999; Elliot, et al., 2016) and the 12 capacities of the M-Axis of the PDM-2 (Lingiardi \& McWilliams, 2017). In this sense, the use of $P P Q$ would help clinicians integrate both nomothetic and idiographic approaches, reducing the clinical and empirical debate on the polarity attributed to these two different types of knowledge. Indeed, this integration, as also claimed by the authors Dazzi, Lingiardi and Gazzillo (2009), would represent an optimal choice to manage the tension inherent in every diagnostic process, in which the clinician is called to both recognize the similarities between the subject under examination and the other subjects, psychometrically comparing the person with a normative group (nomothetic perspective), and to grasp the individual's uniqueness and peculiarities that differentiate a person from all other people (idiographic perspective), towards a broader and more authentic understanding of the client.

\section{Conclusion}

In this study we present, for the first time in literature, a PGOM namely the PPQ, applied to a case of illusory mental health. The quantitative data place the client within the healthy population threshold, although the clinical observation detects significant subjective suffering. Self-reports are generally unable to detect suffering. There are nomothetic proxy questionnaire, such as the HDRS, able to detect suffering, but there are not idiographic proxy instruments, other than the therapist-generated notes of the sessions, to capture the most implicit aspects of suffering, which are influenced by social desirability or self-deception, and therefore excluded from the client's awareness. The $P P Q$ allows the practitioner to systematically detect and measure the suffering of the client, and to monitor the change during therapy. Also, it demonstrates correspondence with the PDC-2.

The PPQ is an idiographic, therapist-generated, implicit version of $P Q$ that allows a single clinician, observer or researcher to:

- $\quad$ systematically collect the therapist's observations regarding the client's suffering in predefined areas (symptoms, mood, performance, relationships, self-esteem);

- investigate pervasiveness and severity in these predefined areas:

- observe which of these predefined areas could give rise to suffering;

- replace self-report when not available or not recommended (in order to not overwhelm the client during data collection, and to avoid selfdeception and social desirability that often occurs in cases of illusory mental health).

- collect information on the client in a nonnomothetic way;

- exert an idiographic procedure that is systematic, verifiable and replicable and that, therefore, has a solid and valuable methodological validity.

- These PPQ mentioned advantages can guide practitioners to formulate a guided clinical judgment about client's conscious, preconscious and unconscious conflict and feelings, and also to monitor explicit and implicit dimensions of client's suffering, as well as concerning the therapy process and outcome.

Furthermore, we believe that this new idiographic, "practitioner-rated" and implicit version of PQ (PPQ) can be useful to eventually meet the therapist's $P Q$ (in the "proxy" version) with the client's PQ (in the 


\begin{tabular}{|c|c|c|}
\hline Common Psy-Areas & $\begin{array}{c}\text { PPQ's categories } \\
\text { (PQ; Elliot, et al., 2015). }\end{array}$ & $\begin{array}{c}\text { PDC-2's capacities } \\
\text { (Gordon \& Bornstein, 2015) }\end{array}$ \\
\hline Impulse Regulation & $\begin{array}{c}\text { Symptoms } \\
\text { Problem 2= "I would like to better } \\
\text { manage my anger" }\end{array}$ & $\begin{array}{l}\text { 1. Regulation, attention and } \\
\text { learning } \\
\text { 7. Impulse control and regulation }\end{array}$ \\
\hline Emotional Regulation & $\begin{array}{c}\text { Mood } \\
\begin{array}{c}\text { Problem } 1=\text { "I can't get angry with } \\
\text { my father"; }\end{array} \\
\begin{array}{c}\text { Problem 3= "I feel invaded when I } \\
\text { get provoked" }\end{array}\end{array}$ & $\begin{array}{l}\text { 2. Affective range, communication } \\
\text { and understanding } \\
\text { 8. Defensive functioning }\end{array}$ \\
\hline Mentalization & $\begin{array}{c}\text { Specific Performance } \\
\text { Problem } 5=\text { "I protect myself in } \\
\text { the wrong way"; }\end{array}$ & $\begin{array}{l}\text { 3. Mentalization and reflective } \\
\text { functioning } \\
\text { 9. Adaptation, resiliency and } \\
\text { strength } \\
\text { 10. Self-observing capacities } \\
\text { (psychological mindedness) }\end{array}$ \\
\hline Intimacy & $\begin{array}{l}\text { Relationships } \\
\text { Problem } 4=\text { "I need to be } \\
\text { recognized otherwise I close" }\end{array}$ & 5. Relationships and intimacy \\
\hline Self & $\begin{array}{c}\text { Self-esteem } \\
\text { Problem } 6=\text { "I do not understand } \\
\text { if two different parts of my Self } \\
\text { can coexist" }\end{array}$ & $\begin{array}{l}\text { 4. Differentiation and integration } \\
\text { (identity) } \\
\text { 6. Self-esteem regulation and } \\
\text { quality of internal experience } \\
\text { 11. Capacity to construct and use } \\
\text { internal standards and ideals } \\
\text { 12. Meaning and purpose }\end{array}$ \\
\hline
\end{tabular}

Table 7: Common-topic psychological areas between PPQ's categories and PDC-2's capacities

simplfied version (Elliot, 1999, Elliot et al., 2016;). This use of the PPQ could provide, therefore, some valuable investigation material for future research to analyze what Dazzi and colleagues (2009) define one

of the most disregarded aspect of the diagnostic process, namely the clinician's subjective experience of the relationship with the client. Indeed, the clinician's subjective experience could be considered a resource, rather than a source of error, where, as in the case of $P P Q$, it is included in the diagnostic process through the use of systematized, valid and reliable methodological strategies, and also through a required specific training that guides the clinician to reflect on the implicit and explicit experience of relationship with clients, as well as to recognize personal style and the subjective impact on the personality of the clients. Accordingly, we believe that PPQ is also an instrument that can be used especially by clinicians in training to test and self-develop their skills as professionals (as explained above), or during supervision in the clinical context. Here we just mention these topics, but we do not exclude that we will address it in the near future.

This results suggest a reflection about contract in Transactional Analysis. As known, the therapeutic contract is an agreement between the client and the therapist to focus and achieve a well-defined objective to work on treatment, which varies according to the level of the contract. Not all clients are able to work with the therapist at a certain level of contract, and therefore need to work first on lower level contracts. In this sense, the contract is also a direct way to measure therapeutic progress. For this reason it is very important for the therapist to be well attuned to the possibility and availability of clients to move from one 
level of contract to another, and therefore with their wishes and needs. According to Loomis (1982), it is this flexibility that allows clients to change in relation to their subjective times. Accordingly, the choice of the most suitable timing to stimulate the client to move from one level of contract to another is one of the fundamental aspects of therapeutic work (Loomis, 1982). The PPQ can be understood as a therapist instrument to draw up an implicit contract with the client, in cases in which clients are not able to describe aspects of their suffering because of a defence against the awareness of threatening memories and emotions. The PPQ may be helpful to the therapist within the theoretical frame of transactional analysis both to focus on the client's implicit sufferings, and to monitor the client's changes during the course of therapy, even for those implicit dimensions that cannot be contractualised.

Giulia Guglielmetti, clinical psychologist, masters degree in Dynamic Clinical Psychology at the University of Padua, can be contacted at: giulia.guglielmetti.psy@gmail.com

Enrico Benelli PhD, Provisional Teaching and Supervising Transactional Analyst (Psychotherapy) (PTSTA-P), Vice-President of CPD (Centre for Dynamic Psychology) in Padua (Italy), Adjunct Professor of Dynamic Psychology, University of Padua, can be contacted at: enrico.benelli@unipd.it

\section{References}

Allport, G. (1960). Personality and social encounter. Boston: Beacon Press.

American Psychiatric Association. (2013). The Diagnostic and Statistical Manual of Mental Disorders (5th Ed.).

Washington, DC: Author.

https://doi.org/10.1176/appi.books.9780890425596

Barisone, M. G., Lerda, S., Ansaldi, S., De Vincenzo E., \& Angelini, G. (2004). Psychopathology and epilepsy: clinical experience in a centre for the diagnosis and care of epilepsy. Journal of Psychopathology, 10 (3). https://www.jpsychopathol.it/issues/2004/vol103/barisone.html accessed 22 February 2020

Beck, A. T., Steer, R. A., \& Brown, G. K. (1996). BDI-II, Beck Depression Inventory: Manual (2nd ed.). Boston: Harcourt Brace. https://doi.org/10.1037/t00742-000

Benelli, E., De Carlo, A., Biffi, D., \& McLeod, J. (2015). Hermeneutic Single Case Efficacy Design: A systematic review of published research and current standards. Testing, Psychometrics, Methodology in Applied Psychology, 22, 97-133. DOI:10.4473/TPM22.1.7

Bohart, A. C, Berry, M., \& Wicks, C. (2011). Developing a Systematic Framework for Utilizing Discrete Types of Qualitative Data as Therapy Research Evidence. Pragmatic Case Studies in Psychotherapy, 7 (1), Article 9, 145-155. https://doi.org/10.14713/pcsp.v7i1.1076
Bohart, A.C., Tallman, K.L., Byock, G., \& Mackrill, T. (2011). The "Research Jury" Method: The application of the jury trial model to evaluating the validity of descriptive and causal statements about psychotherapy process and outcome. Pragmatic Case Studies in Psychotherapy, 7 (1), Article 8, 101-144. https://doi.org/10.14713/pcsp.v7i1.1075

Bram, A.D., Gottschalk, K.A., \& Leeds, W.M. (2018). Chronic fatigue syndrome and the somatic expression of emotional distress: Applying the concept of illusory mental health to address the controversy. Journal of Clinical Psychology 75 (1) 116-131 Publ. 2019 https://doi.org/10.1002/jclp.22692

Caputo, A. (2017). Social desirability bias in self-reported well-being measures: evidence from an online survey. Universitas Psychologica, 16(2), 1-13.

https://doi.org/10.11144/Javeriana.upsy16-2.sdsw

Cousineau, T. M., \& Shedler, J. (2006). Predicting physical health: implicit mental health measures versus self-report scales. The Journal of Nervous and Mental Disease, 194 (6), 427- 432. https://doi.org/10.1097/01.nmd.0000221373.74045.51

Dazzi, N., Lingiardi, V., \& Gazzillo, F. (2009). La diagnosi in psicologia clinica. Personalità e psicopatologia. Milano: Raffaello Cortina.

Elliott, R., Shapiro, D. A., \& Mack, C. (1999). Simplified Personal Questionnaire procedure manual. Toledo, $\mathrm{OH}$ : University of Toledo.

Elliott, R., Slatick, E., \& Urman, M. (2001). Qualitative change process research on psychotherapy: Alternative strategies. Psychologische Beiträge, 43, 69-111.

Elliott, R., Wagner, J., Sales, C. M., Rodgers, B., Alves, P., \& Café, M. (2016). Psychometrics of the Personal Questionnaire: A client-generated outcome measure. Psychological Assessment, 28 (3), 263-278. https://doi.org/10.1037/pas0000174

Evans, C., Connell, J., Barkham, M., Margison, F., MellorClark, J., McGrath, G., e Audin, K. (2002). Towards a standardised brief outcome measure: Psychometric properties and utility of the CORE-OM. British Journal of Psychiatry, 180, 51-60. https://doi.org/10.1192/bjp.180.1.51

Ghisi, M., Flebus, G. B., Montano, A., Sanavio, E., \& Sica, C. (2006). Beck Depression Inventory-Second Edition. Adattamento italiano: Manuale. Firenze: Organizzazioni Speciali (O-S).

Gordon, R. M. \& Bornstein, R. F. (2015). Brief Manual for the Psychodiagnostic Chart-2 (PDC-2) A Practical Tool to Operationalize the PDM-2 and Integrate It with the ICD and DSM.

https://www.researchgate.net/publication/288004361 Brief Manual for the Psychodiagnostic Chart-2 PDC2 A Practical Tool to Operationalize the PDM2 and Integrate It with the ICD and DSM accessed 22 February 2020 
Gordon, R. M., \& Bornstein, R. F. (2012). The Psychodiagnostic Chart: A practical tool to integrate and operationalize the PDM with the ICD or DSM. Retrieved from http://www.mmpiinfo.com/pdm-blog - no longer accessible 22 February 2020

Gordon, R. M. \& Bornstein, R. F. (2015). The Psychodiagnostic Chart-2 v.8.1 (PDC-2), DOI: 10.13140/RG.2.1.3905.4169.

Gordon, R. M., \& Bornstein, R. F. (2018). Construct Validity of the Psychodiagnostic Chart: A Transdiagnostic Measure of Personality Organization, Personality Syndromes, Mental Functioning, and Symptomatology.

https://doi.org/10.1037/pap0000142

Grice, J. W. (2004). Bridging the Idiographic-Nomothetic divide in ratings of self and others on the Big Five. Journal of Personality, 72 (2), 203-

\section{1.https://doi.org/10.1111/j.0022-3506.2004.00261.x}

Hamilton, M. A. (1960). Hamilton Depression Rating Scale (HDRS). J Neurol Neurosurg Psychiatry, 23: 56-62 https://doi.org/10.1136/innp.23.1.56

Huprich, S. K., McWilliams, N., Lingiardi, V., Bornstein, R. F., Gazzillo, F., \& Gordon, R. M. (2015). The Psychodynamic Diagnostic Manual (PDM) and the PDM-2: Opportunities to significantly affect the profession.

Psychoanalytic Inquiry, 35, 60-73.

https://doi.org/10.1080/07351690.2015.987594

Jacobson, N. S., \& Truax, P. (1991). Clinical significance: A statistical approach to defining meaningful change in psychotherapy research. Journal of Consulting and Clinical Psychology, 59, 12-19. https://doi.org/10.1037/0022006X.59.1.12

Lingiardi, V., \& McWilliams, N. (2017). Psychodynamic Diagnostic Manual: Second Edition (PDM-2). New York: Guilford Press.

Lingiardi, V., McWilliams, N., Bornstein, R. F., Gazzillo, F., \& Gordon, R. M. (2015). The Psychodynamic Diagnostic Manual Version 2 (PDM-2): Assessing patients for improved clinical practice and research. Psychoanalytic Psychology, 32(1), 94-115. https://doi.org/10.1037/a0038546

Loomis, M. E. (1982). Contracting for change. Transactional Analysis Journal, 12 (1), 51-54.

https://doi.org/10.1177/036215378201200107

McLeod, J. (2001). An administratively created reality: Some problems with the use of self-report questionnaire measures of adjustment in counselling/psychotherapy outcome research. Counselling and Psychotherapy Research, 1 (3), 215-226. https://doi.org/10.1080/14733140112331385100

McLeod, S. A. (2007). Nomothetic idiographic debate. Retrieved from

https://www.simplypsychology.org/nomotheticidiographic.html
Millon, T. (1991). Classification in psychopathology: Rationale, alternatives, and standards". Journal of Abnormal Psychology, 100(3), 245-261. https://doi.org/10.1037/0021843X.100.3.245

Pagnini, F., Gibbons, C. J., \& Castelnuovo (2012). The importance of an idiographic approach for the severe chronic disorders - the case of the amyotrophic lateral sclerosis patient. Frontiers in Psychology, 3: 509 https://doi.org/10.3389/fpsyg.2012.00509

Palmieri, G. (2011). La valutazione degli interventi psicologici tramite il CORE-OM. Unpublished document from the conference at Casa di Cura Villa Igea, Trieste.

Paulhaus, D. L. (1986). Self-deception and impression management in test responses. In Angleitner A and Wiggins JS (eds) Personality Assessment via Questionnaires: Current Issues in Theory and Measurement. Berlin: Springer-Verlag. https://doi.org/10.1007/978-3-642-70751$\underline{38}$

Reich, R. R., Below, M. C., \& Goldman, M. S. (2010) Explicit and Implicit Measures of Expectancy and Related Alcohol Cognitions: A Meta-Analytic Comparison. Psychology of Addictive Behaviors, 24 (1), 13-25. https://doi.org/10.1037/a0016556

Shedler, J., Mayman, M., \& Manis, M. (1993). The illusion of mental health. American Psychologist, 48 (11), 1117-1131. https://doi.org/10.1037/0003-066X.48.11.1117

Shedler, J., Karliner, R. and Katz, E. (2003). Cloning the clinician: A method for assessing illusory mental health. Journal of Clinical Psychology, 59(6), 635-650. https://doi.org/10.1002/jclp.10148

Sinha, N., \& Glass A. (2017). Dissociating medial temporal and striatal memory systems with a same/different matching task: Evidence for two neural systems in human recognition. Journal of General Psychology, 144, 110 - 129. https://doi.org/10.1080/00221309.2016.1276044

Spielberger, C. D., Gorsuch, R. L., Lushene, R., Vagg, P. R., e Jacobs, G. A. (1983). Manual for the State-Trait Anxiety Inventory. Palo Alto, CA: Consulting Psychologists Press.

Spitzer, R. L., Kroenke, K., \& Williams, J. B. (1999). Validation and utility of a self-report version of PRIME-MD: the PHQ primary care study. Journal of the American Medical Association. Nov 10; 282:18, 1737-44. https://doi.org/10.1001/jama.282.18.1737

Subic-Wrana, C., Bruder, S., Thomas, W., Lane, R., Köhle, K. (2005). Emotional Awareness Deficits in Inpatients of a Psychosomatic Ward: A Comparison of Two Different Measures of Alexithymia. Psychosomatic Medicine, 67 (3):483-489. https://doi.org/10.1097/01.psy.0000160461.19239.13

Ward, G., \& McLeod, J. (2018, June). Case analysis of sources of outcome data in pluralistic counselling for a client 
suffering from childhood trauma. Paper delivered at Society for Psychotherapy Research Annual Conference,

Amsterdam.

Westen, D., Gabbard, G., \& Blagov, P. (2006). Back to the future: Personality structure as a context for psychopathology. In R. F. Krueger \& J. L. Tackett (Eds.), Personality and psychopathology: Building bridges (pp. 335384). New York: Guilford Press.

Westen, D., \& Shedler, J. (2007). Personality diagnosis with the Shedler-Westen Assessment Procedure (SWAP): integrating clinical and statistical measurement and prediction. Journal of Abnormal Psychology, 116: 810-822. https://doi.org/10.1037/0021-843X.116.4.810

Widdowson, M. (2012c). TA treatment of depression: a hermeneutic single-case efficacy design study- case three:
"Tom". International Journal of Transactional Analysis Research, 3 (2), 15-27. https://doi.org/10.29044/v3i2p15

Widdowson, M. (2014). Transactional analysis psychotherapy for a case of mixed anxiety \& depression: A pragmatic adjudicated case study - 'Alastair". International Journal of Transactional Analysis Research, 5 (2), 66-76. https://doi.org/10.29044/v5i2p66

Wineke, J., Eurelings-Bontekoe, E., Dijke, A.V., Moene, F., Gool, A.V. (2015). Do Patients with Somatoform Disorders Present with Illusory Mental Health? Journal of Psychology \& Psychotherapy 5: 213. https://doi.org/10.4172/2161$\underline{0487.1000213}$

World Health Organisation (1992) ICD-10 Classification of Mental and Behavioural Disorders. Geneva: Author. 


\section{Appendix: Table A: PPQ for Phase 1}

\begin{tabular}{|c|c|c|c|c|c|}
\hline Suffering & Patient's Words & Source & Area & $\begin{array}{c}\text { Pervasivene } \\
\text { ss } \\
\text { (minutes } \\
\text { expressed in } \\
\text { percentage) }\end{array}$ & $\begin{array}{c}\text { Severity } \\
\text { (perceived and } \\
\text { expressed by } \\
\text { the researcher } \\
\text { on a scale 1- } \\
10^{*} \text { ) }\end{array}$ \\
\hline $\begin{array}{l}\text { 1) I CAN'T GET } \\
\text { ANGRY WITH } \\
\text { MY FATHER }\end{array}$ & 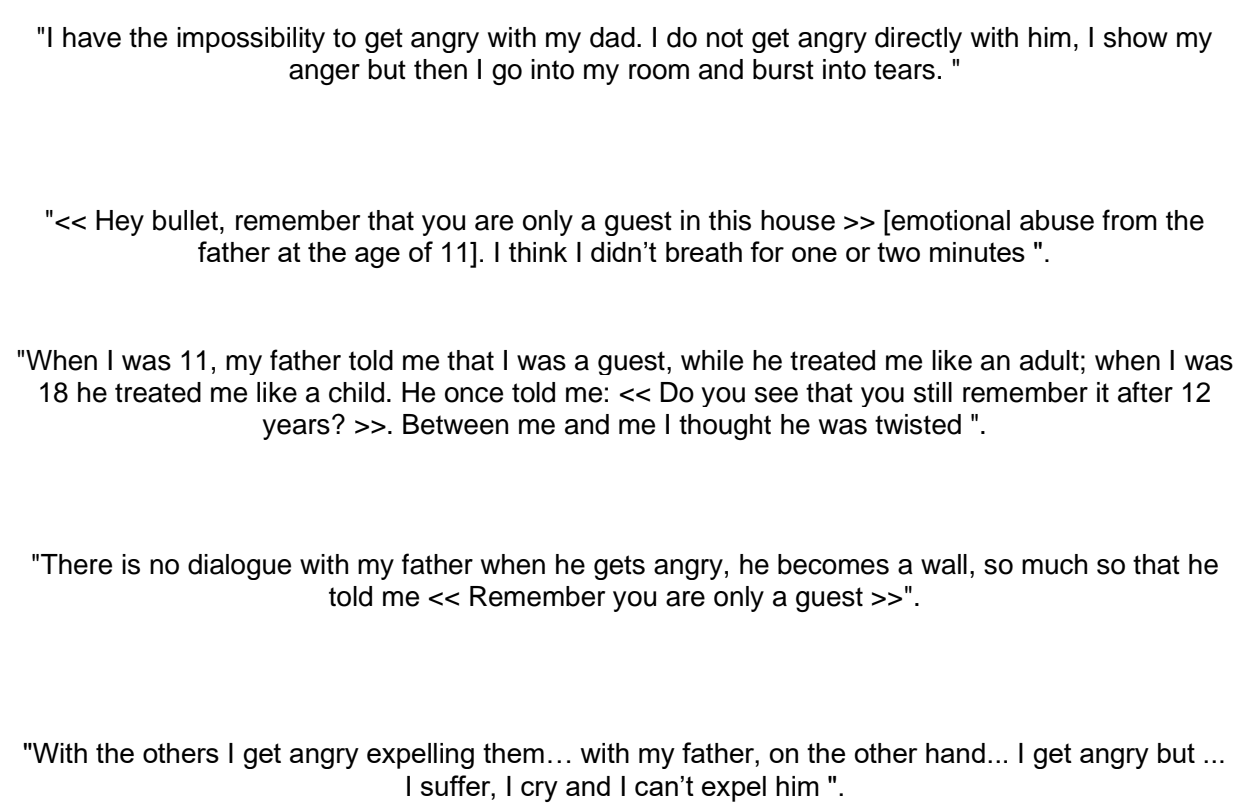 & $\begin{array}{l}\text { (Sess 1, line } \\
\text { 249) } \\
\\
\text { (Sess 5, line } \\
\text { 278) } \\
\\
\text { (Sess 5, line } \\
\text { 287). } \\
\\
\\
\text { (Sess 5, line } \\
\text { 318) } \\
\\
\text { (Sess 7, line } \\
\text { 381) }\end{array}$ & Mood & $16 \%$ & $\begin{array}{c}5 \\
\text { Almost strong }\end{array}$ \\
\hline
\end{tabular}




\begin{tabular}{|c|c|c|c|c|c|}
\hline $\begin{array}{l}\text { 2) I WOULD } \\
\text { LIKE TO } \\
\text { BETTER } \\
\text { MANAGE MY } \\
\text { ANGER }\end{array}$ & $\begin{array}{l}\text { "The thing that most ... presses me, I wish not to be angry anymore, it is not to get angry anymore. } \\
\text { That is in the sense, get angry but with control. When I get angry I become really blind, anger is my } \\
\text { burden". } \\
\text { "As a child I was considered a little rough, I liked fighting games ... regardless of males, females ... } \\
\text { just that ... just that ... it makes me feel bad because I still create more suffering ". } \\
\text { "I intimidate people generally. I scare them. I do not want to hurt, but I scare them "[when he reacts } \\
\text { instinctively]. } \\
\text { "With anger I threw out the pain". }\end{array}$ & $\begin{array}{l}\text { (Sess 1, line } \\
63) \\
\\
\text { (Sess 1, line } \\
71) \\
\\
\text { (Sess 3, line } \\
\text { 150) } \\
\text { (Sed 5, line } \\
\text { 352) }\end{array}$ & Symptoms & $8 \%$ & $\begin{array}{c}6 \\
\text { Moderate }\end{array}$ \\
\hline $\begin{array}{c}\text { 3) I FEEL } \\
\text { INVADED } \\
\text { WHEN I GET } \\
\text { PREVARICATE } \\
\text { D }\end{array}$ & $\begin{array}{l}\text { "It happens that I physically intimidate people... But not beating them, just tugging them ... when I } \\
\text { feel invaded, when I feel invaded ". } \\
\text { "Precedence is mine and you must give it to me, I've never seen it like this before. Transferred } \\
\text { within [the aggressive behavior] is an imposing.... p prevarication in short." } \\
\text { "T: The rules become an enemy to be demolished, to crash ... } \\
\text { P: Oh, because I've always lived in the midst of norms ... that were too tight for me... [example] I } \\
\text { never came home on time ... [example]. More my dad told me to study, less I studied". }\end{array}$ & $\begin{array}{l}\text { (Sess 1, line } \\
\text { 268) } \\
\\
\text { (Sess 2, line } \\
\text { 22) } \\
\\
\\
\text { (Sess 5, line } \\
163)\end{array}$ & Mood & $7 \%$ & $\begin{array}{c}7 \\
\text { Almost } \\
\text { moderate }\end{array}$ \\
\hline $\begin{array}{l}\text { 4) I NEED TO } \\
\text { BE } \\
\text { RECOGNIZED } \\
\text { OTHERWISE I } \\
\text { CLOSE } \\
\text { RELATIONSHIP } \\
\quad \text { S }\end{array}$ & $\begin{array}{l}\text { "With my ex-girlfriend it's over for the same reasons that I'm frustrated because of my parents, that } \\
\text { is to be not recognized ... I stopped loving her because once I was really exposed and I had nerves } \\
\text { uncovered, she just rejected, wall, I have not been able to love her anymore ". } \\
\text { "If people do not recognize me, I close the relationships." }\end{array}$ & $\begin{array}{l}\text { (Sess 1, line } \\
290) \\
\text { (Sess 5, line } \\
\text { 452) }\end{array}$ & Relationships & $18 \%$ & $\begin{array}{c}5 \\
\text { Almost strong }\end{array}$ \\
\hline
\end{tabular}




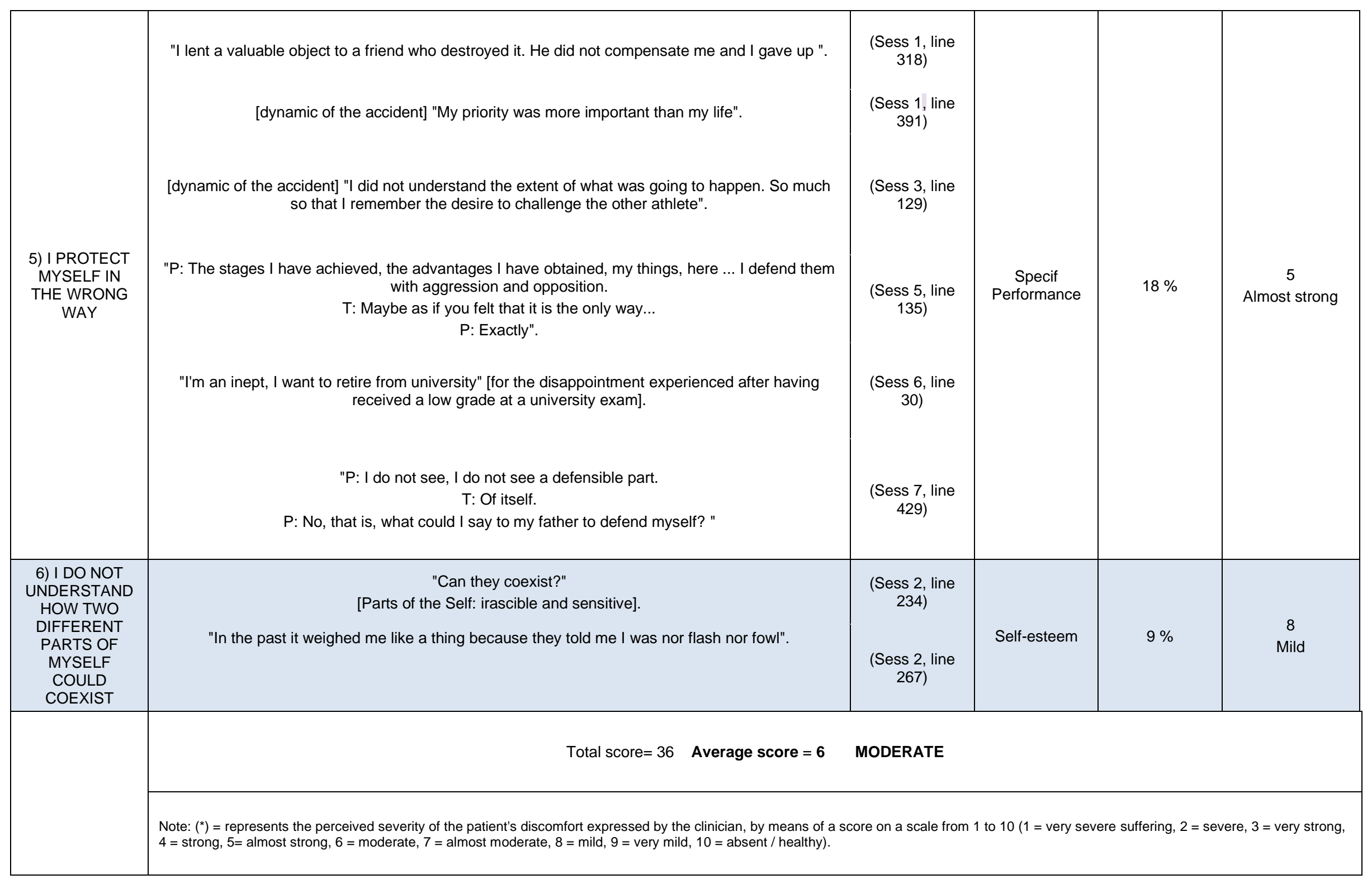


Appendix: Table B: PPQ for Phase 2

\begin{tabular}{|c|c|c|c|c|c|}
\hline Suffering & Patient's Words & Source & Area & $\begin{array}{l}\text { Pervasiven } \\
\text { ess } \\
\text { (minutes } \\
\text { expressed in } \\
\text { percentage) }\end{array}$ & $\begin{array}{l}\text { Severity } \\
\text { (perceived and } \\
\text { expressed by } \\
\text { the researcher } \\
\text { on a scale } 1 \text { - } \\
10^{*} \text { ) }\end{array}$ \\
\hline $\begin{array}{l}\text { 1) I CAN'T GET } \\
\text { ANGRY WITH } \\
\text { MY FATHER }\end{array}$ & $\begin{array}{l}\text { "T: Your father could come to greet you after work, rather than demanding that his children should } \\
\text { do it... I mean, what was it like for you to go downstairs? [..] } \\
\text { P: P: Sometimes inconvenient and unpleasant because maybe I was doing something that } \\
\text { interested me. Maybe I was studying all afternoon, he was coming and I had to give up everything, } \\
\text { go down, say hello, waist an hour... waist it, yes. } \\
\text { T: T: Well, waist... It says a lot about how you perceived it. " } \\
\text { "I told him < Dad, you are a foolish man... to show a feeling is not that bad ... >> ". } \\
\text { "I mean, I knew there was a ... a ... how to say, a crostified core, unchanged and not processed like } \\
\text { that ... I had absorbed it and that is". } \\
\text { "Yes, enough. I do not have to prove anything to my father. " }\end{array}$ & $\begin{array}{l}\text { (Sess 9, lines } \\
404-409) . \\
\\
\text { (Sess 10, line } \\
347) \\
\\
\text { (Sess 12, lines } \\
\text { 165-167) } \\
\\
\\
\text { (Sess 14, line } \\
167)\end{array}$ & Mood & $32 \%$ & $\begin{array}{c}7 \\
\text { Almost } \\
\text { moderate }\end{array}$ \\
\hline $\begin{array}{l}\text { 2) I WOULD } \\
\text { LIKE TO } \\
\text { BETTER } \\
\text { MANAGE MY } \\
\text { ANGER } \\
\text { Cont/ }\end{array}$ & $\begin{array}{l}\text { "I wonder why I have to ... for the affections I need to use an expulsive way, while the others are } \\
\text { more resilient and more introspective, so l'm asking myself questions ...". } \\
\text { "I gave myself permission to listen, I did not get angry when they told me }<<\text { No }>>\text {. I tried to } \\
\text { understand the motivations, to listen ...". }\end{array}$ & $\begin{array}{l}\text { (Sess 10, line } \\
232) \\
\text { (Sess } 11, \text { lines } \\
\text { 329-330) }\end{array}$ & Symptoms & $8 \%$ & $\begin{array}{c}9 \\
\text { Very mild }\end{array}$ \\
\hline
\end{tabular}




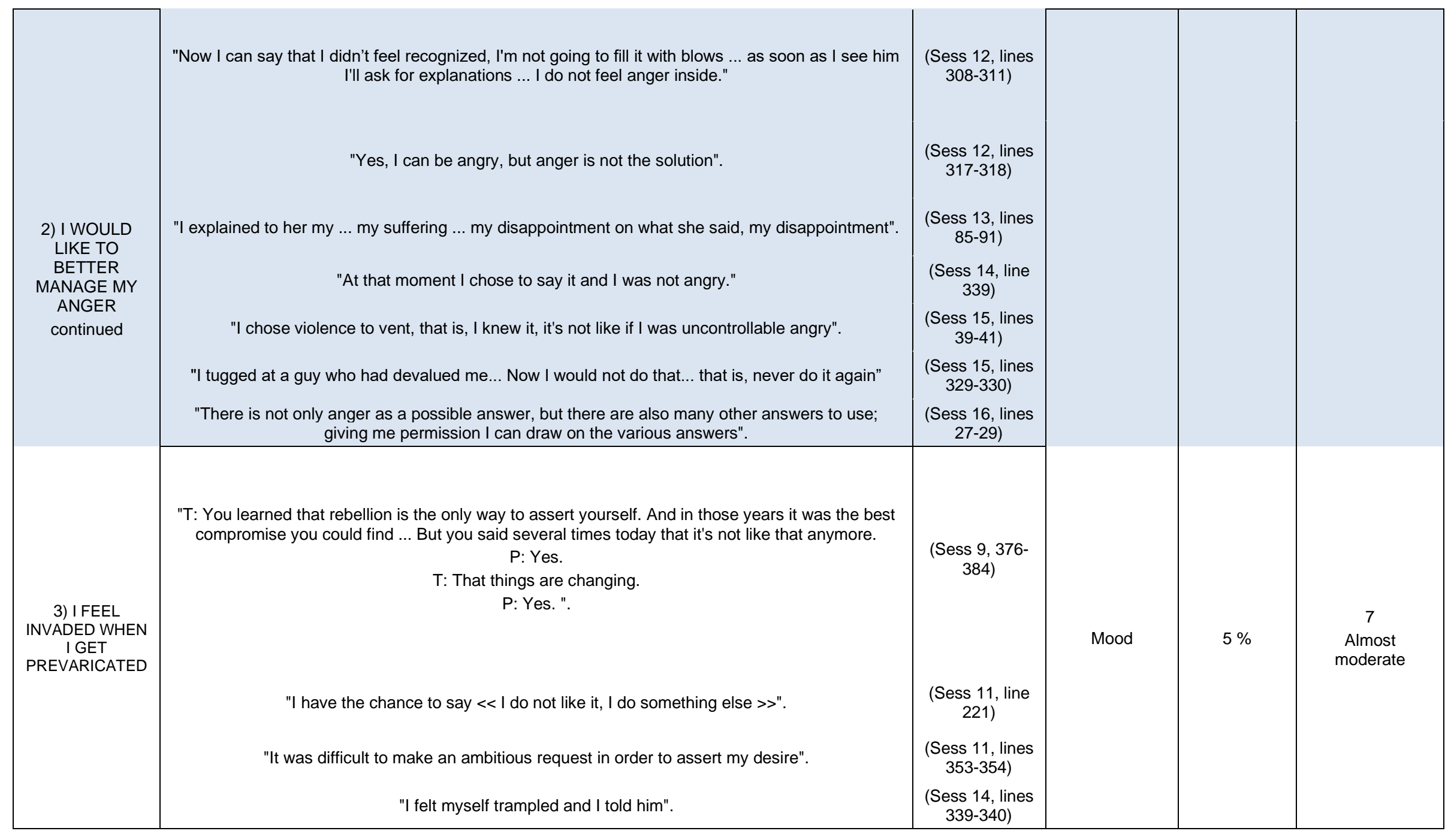




\begin{tabular}{|c|c|c|c|c|c|}
\hline \multirow[t]{2}{*}{$\begin{array}{l}\text { 4) I NEED TO BE } \\
\text { RECOGNIZED } \\
\text { OTHERWISE I } \\
\text { CLOSE } \\
\text { RELATIONSHIPS }\end{array}$} & 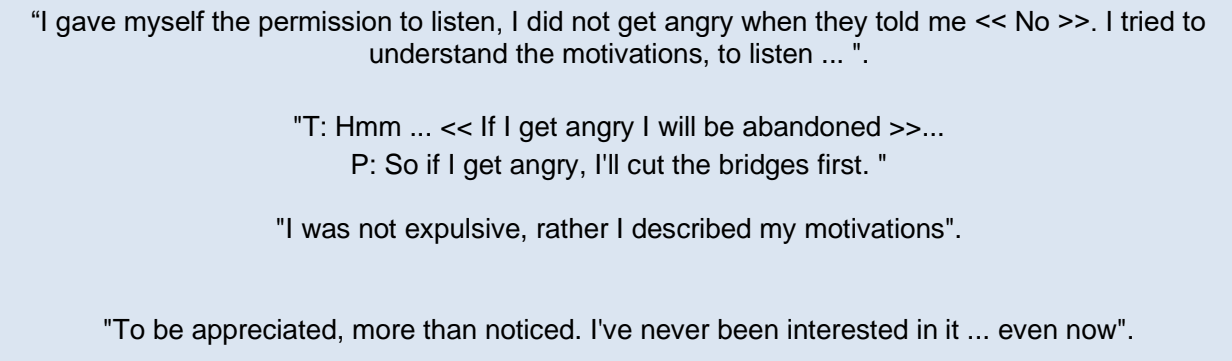 & $\begin{array}{l}\text { (Sess } 11 \text {, lines } \\
\text { 329-330) } \\
\text { (Sess } 12 \text {, lines } \\
\text { 388-389) } \\
\text { (Sess } 13 \text {, line } \\
\quad 96) \\
\text { (Sess } 13 \text {, line } \\
\text { 303-304) }\end{array}$ & \multirow[t]{2}{*}{ Relationships } & \multirow[t]{2}{*}{$13 \%$} & \multirow[t]{2}{*}{$\begin{array}{c}7 \\
\text { Almost } \\
\text { moderate }\end{array}$} \\
\hline & $\begin{array}{l}\text { "When someone defines me, he says more than himself, rather than me. It was really an } \\
\text { enlightenment... I had never thought about it, after all I felt it ". }\end{array}$ & $\begin{array}{l}\text { (Sess } 16, \text { lines } \\
\text { 323-325) }\end{array}$ & & & \\
\hline $\begin{array}{l}\text { 5) I PROTECT } \\
\text { MYSELF IN } \\
\text { THE WRONG } \\
\text { WAY }\end{array}$ & $\begin{array}{l}\text { "I went there and I politely asked him << Excuse me, can I ask you something? >>"... I do not think } \\
\text { I bothered him. Anyway, my opinion about him does not change. " } \\
\text { "I gave myself permission to listen to both the pros and cons". } \\
\text { "It was difficult for me to make an ambitious request in order to assert my desire". } \\
\text { "I protected myself with anger". } \\
\text { "I acquired a bit of self-awareness from this point of view... I give up my priority but at the same } \\
\text { time I know that I save my life, I avoid fatigue, and suffering in general". } \\
\text { "Then it is useless to complain, that's not bravery!" } \\
\text { "Now I see other possibilities to defend myself, to survive". }\end{array}$ & $\begin{array}{l}\text { (Sess 10, lines } \\
47-47) \\
\text { (Sess } 11,326) \\
\text { (Sess } 11 \text {, lines } \\
\text { 353-354) } \\
\text { (Sess } 12 \text {, line } \\
106) \\
\text { (Sess } 14, \text { lines } \\
215-220) \\
\text { (Sess } 14, \text { lines } \\
176-178) \\
\text { (Sess } 16, \text { line } \\
41 \text { ) }\end{array}$ & $\begin{array}{c}\text { Specific } \\
\text { Performance }\end{array}$ & $7 \%$ & $\begin{array}{c}9 \\
\text { Very mild }\end{array}$ \\
\hline
\end{tabular}




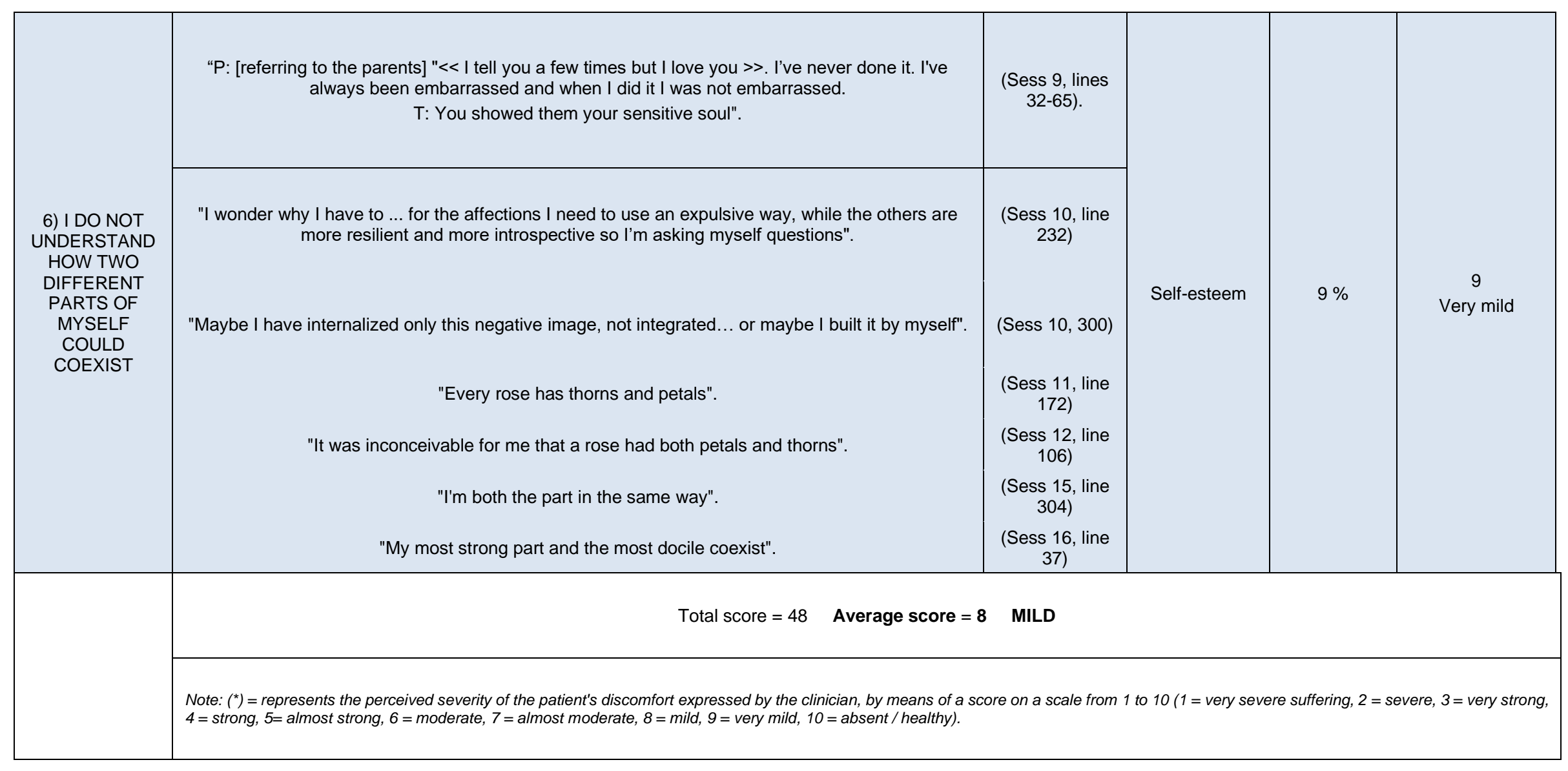




\section{Appendix: Table C: PPQ for Phase 3}

\begin{tabular}{|c|c|c|c|c|}
\hline $\begin{array}{l}\text { Suffering } \\
\text { (Client) }\end{array}$ & Patient's Words & Source & Area & $\begin{array}{l}\text { Severity } \\
\text { (perceived and } \\
\text { expressed by the } \\
\text { researcher on a scale } 1 \text { - } \\
10^{*} \text { ) }\end{array}$ \\
\hline $\begin{array}{l}\text { 1) I CAN'T GET } \\
\text { ANGRY WITH MY } \\
\text { FATHER }\end{array}$ & $\begin{array}{l}\text { "I give myself permission to feel emotions that I did not feel before, especially within the family } \\
\text { environment". }\end{array}$ & (Cl, lines 67-72) & Mood & $\begin{array}{c}8 \\
\text { Mild }\end{array}$ \\
\hline $\begin{array}{l}\text { 2) I WOULD LIKE } \\
\text { TO BETTER } \\
\text { MANAGE MY } \\
\text { ANGER }\end{array}$ & $\begin{array}{l}\text { "I spend much less time being angry, I give myself permission to feel emotions that I did not feel } \\
\text { before". } \\
\text { "Before reacting with anger, I allow myself to analyze and evaluate, even in unpleasant situations". }\end{array}$ & $\begin{array}{c}(\mathrm{Cl}, \text { line } 70) \\
(\mathrm{Cl}, \text { lines } 81-83)\end{array}$ & Symptoms & $\begin{array}{l}9 \\
\text { Very mild }\end{array}$ \\
\hline $\begin{array}{l}\text { 3) I FEEL } \\
\text { INVADED WHEN I } \\
\text { GET } \\
\text { PREVARICATED }\end{array}$ & $\begin{array}{c}\text { "Therapy has encouraged my self-awareness and has highlighted new points of view that were } \\
\text { previously inaccessible to me". }\end{array}$ & (Cl, lines 167-168) & Mood & $\begin{array}{c}8 \\
\text { Mild }\end{array}$ \\
\hline $\begin{array}{l}\text { 4) I NEED TO BE } \\
\text { RECOGNIZED } \\
\text { OTHERWISE I } \\
\text { CLOSE } \\
\text { RELATIONSHIPS }\end{array}$ & $\begin{array}{l}\text { "I have learned to establish a relationship of trust with a stranger". } \\
\text { "Before reacting with anger, I allow myself to analyze and evaluate, even in unpleasant situations". }\end{array}$ & $\begin{array}{c}(\mathrm{Cl}, \text { line } 164) \\
(\mathrm{Cl}, \text { lines } 81-83)\end{array}$ & Relationship & $\begin{array}{c}8 \\
\text { Mild }\end{array}$ \\
\hline $\begin{array}{l}\text { 5) I PROTECT } \\
\text { MYSELF IN THE } \\
\text { WRONG WAY }\end{array}$ & $\begin{array}{l}\text { "I give myself permission to feel emotions that I did not feel before". } \\
\text { "Now I can admit my faults and mistakes". } \\
\text { "I have achieved greater awareness". } \\
\text { "Before reacting with anger, I allow myself to analyze and evaluate, even in unpleasant situations". }\end{array}$ & $\begin{array}{c}(\mathrm{Cl}, \text { line } 70) \\
(\mathrm{Cl}, \text { line } 90) \\
(\mathrm{Cl}, \text { line } 137) \\
(\mathrm{Cl}, \text { lines } 81-83)\end{array}$ & $\begin{array}{l}\text { Specific } \\
\text { Performance }\end{array}$ & $\begin{array}{c}9 \\
\text { Very mild }\end{array}$ \\
\hline
\end{tabular}




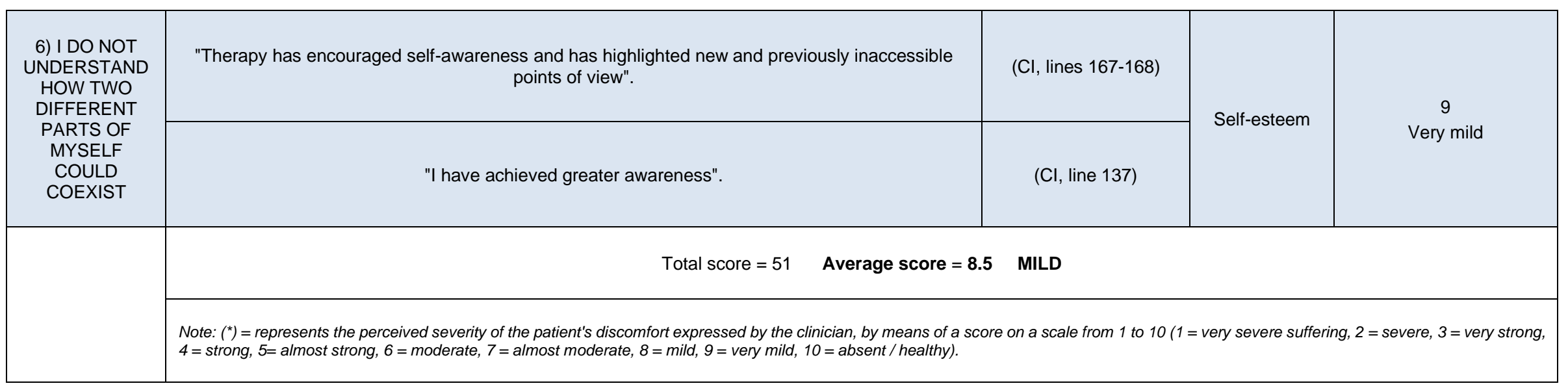

